\title{
Situating Educational Computing Doctoral Students in a Community of Practice: A Rubric-driven, Online Portfolio System
}

\author{
Mary Jo Dondlinger and James G. Jones \\ University of North Texas, Denton, Texas, USA
}

mjdondlinger@gmail.com gjones@unt.edu

\begin{abstract}
This article describes the theoretical basis and design considerations for a rubric-driven, online portfolio system. The system was created for students in the educational computing doctorate to organize and distribute the body of scholarly works generated throughout the coursework phase of their academic program. Based on theories of situated and distributed cognition, this rubricdriven online portfolio system provides a consistent means of assessing performance and offers a contextually authentic method of artifact distribution. Moreover, the portfolio system promotes an ongoing dialogue between faculty members and students regarding the values and practices in the educational technology field.
\end{abstract}

Keywords: Doctoral portfolio, doctoral exams, doctoral assessment rubric, situated learning, communities of practice.

\section{Introduction}

Research has shown that students better conceptualize knowledge that is acquired in a learning context that closely matches or is "situated in" its real-world context (Brown, Collins, \& Duguid, 1989; Cognition and Technology Group, 1990; Harmon \& Jones, 2001). As early as the 1800s, pragmatists such as Dewey $(1925,1938)$ argued that instruction that was anchored in an authentic context provided better learning. More recently, Lave and Wenger (1991) specifically spelled out principles of situated cognition, citing the role of interaction with other actors in a knowledge domain or community of practice as a significant component of situated learning. These principles were applied in the development of a portfolio used in the assessment for candidacy in a doctoral program in educational computing at a Sun Belt, mid-sized university in the southwestern United States, but apply equally well to portfolio assessments at any level of education (Barrett, 2007; Juniewicz, 2003; Pullman, 2002). Students participate in an educational computing community of practice throughout their coursework by preparing this portfolio.

Material published as part of this publication, either on-line or in print, is copyrighted by the Informing Science Institute. Permission to make digital or paper copy of part or all of these works for personal or classroom use is granted without fee provided that the copies are not made or distributed for profit or commercial advantage AND that copies 1) bear this notice in full and 2) give the full citation on the first page. It is permissible to abstract these works so long as credit is given. To copy in all other cases or to republish or to post on a server or to redistribute to lists requires specific permission and payment of a fee. Contact Publisher@InformingScience.org to request redistribution permission.
In order for a portfolio assessment to be effective, the means by which it is implemented must provide scaffolding and feedback to learners throughout the portfolio creation process (Segers, Gijbels, \& Thurlings, 2008; Van Tartwijk, Driessen, Van Der Vleuten, \& Stokking, 2007). The paper-based means of assembling and distributing student portfolios to faculty members did not allow ongoing feedback throughout the crea- 
tion process, nor was this approach consistent with practices in a technology-based program. To complicate matters further, faculty members' turnover and other events within the program created a degree of confusion over standards and expectations for evaluating this assessment. These issues provided the impetus for designing and developing an online, rubric-driven, portfolio system that was more consistent with practices situated in the educational technology community and provided clearly articulated standards and expectations for students in the program. This article presents the theoretical rationale for this online portfolio system, the objectives of its design, and the means by which the design addresses the problems outlined above.

\section{Theoretical Basis}

Situated cognition is a constructivist approach with its foundation in the socialization theories of Vygotsky (1978), who proposed that cognitive development occurs primarily on a social level. While he did not propose that this development was solely social (indeed, he asserts that later stages of development occur within the individual), he found that this development "applies equally to voluntary attention, to logical memory, and to the formation of concepts. All the higher functions originate as actual relationships between individuals" (p. 57). Constructivists follow this view, not as an autonomous set of facts to be memorized and internalized, but rather as a social process through which learners construct meanings through interactions with others, the material world, and the culture at large. Although cognitive constructivists and sociocultural constructivists debate over the prevalence of internal or external influences on the construction of knowledge, both agree that knowledge construction is situated in a larger sociocultural context and involves engagement with it (Duffy \& Cunningham, 1996). Situated cognition is a sociocultural constructivist approach that sees knowledge as residing in the "individual in social interaction" (Duffy \& Cunningham, 1996, p. 175), as opposed to the single mind of the individual, a cognitive constructivist view.

In addition to this emphasis on the social nature of knowledge construction, situated cognition also gives considerable significance to the "real-world" context in which knowledge is situated and constructed (Harmon \& Jones, 2001). This emphasis is inspired mainly by the ontological philosophy of Heidegger and Deweyan pragmatism. Heidegger (1996) conceptualized human existence as active participation in the world; Duffy and Cunningham (1996) argued that "life, including the vocations, should form the basic context for learning" and that "the learning of any subject is anchored in a larger community or social context" (p. 173). These viewpoints do not differ dramatically from those of Dale (1946), who argued that learning from authentic experience rather than pure abstraction results in more permanent learning and transfer of knowledge.

A related, yet unique, influence on the theory of situated cognition is the work of Gibson (1950, 1979), whose oeuvre spans the fields of ecological psychology, visual perception, design, and ergonomics. Gibson (1950) is most noted for coining the term "affordance," which refers to the interactive possibilities inherent in either an object or an environment. Ecological psychology views humans and animals as players in a complex environmental system, arguing that behavior cannot be fully understood without conceptualizing its role within the larger system or situation (Gibson, 1979). This concept does not differ from that of the authentic context described above; the distinction here is rather on a systems approach, which sees the context, both social and material, and the interactions within it as the basis for knowledge construction.

Situated cognition as a theoretical approach is attributed to Lave (1988) and Wenger (Lave \& Wenger, 1991), who posit that learning routinely occurs as a result of an activity, its context, and the culture in which it is situated, in contrast to classroom learning activities, which are often perceived as abstract and out of context. As Harmon and Jones (2001) put it, "Situated cognition suggests that instruction is most effective when it is offered in the context in which the performance that is being learned will actually occur" (p. 272). The case to be made for situated learning 
is that it is "anchored" (Bransford, Vye, Bateman, Brophy, \& Roselli, 2003) in a context that is more meaningful and real. For example, "learners construct richer and more easily transferable mental models and can more easily solve problems in ill-structured domains if instruction is centered around, or anchored on, a particular problem or set of problems" (Harmon \& Jones, 2001, p. 272).

In a situated context, learners participate in a 'community of practice,' learning not only subject content, but the values and behaviors of that domain - in short, its culture (Lave \& Wenger, 1991). These domain-specific values and behaviors are formed through social interaction within the domain. "Thus learning is constructed," according to Lauzon (1999), "as a process of social interaction that takes place within a framework of participation whereby learners acquire the necessary tools, skills, knowledge, beliefs, and values to actively participate in the community and eventually become a 'master' within the community" (p. 264). For educational computing doctoral students, this means engaging in the activities of an instructional system designer and educational researcher: designing instruction, collecting research data, analyzing the results, and publishing or presenting findings in journals or at conferences. This process of engaging with the domain, beginning at the periphery but moving toward its center with mastery, is what Lave and Wenger (1991) call legitimate peripheral participation. Engagement in authentic tasks within the community of practice immerses learners in the domain while they acquire the explicit knowledge of the domain as well as tacit knowledge about its values and behaviors.

\section{The Educational Computing Portfolio}

These principles of situated cognition form the rationale for assessing educational computing doctoral student learning through a portfolio of domain-specific artifacts, rather than the more traditional comprehensive exams. Requiring students to participate in the educational computing community of practice throughout their coursework situates them in this community of practice from the outset of their studies rather than after program completion. The educational computing doctoral program requires students to demonstrate involvement in this community of practice by defending a portfolio of works in order to become a doctoral candidate and begin dissertation work. This portfolio includes examples of published and unpublished scholarly writing, presentations at professional conferences, and technology-based creative works - artifacts that result from authentic tasks within the educational technology community of practice: publishing, presenting, and designing or developing technology applications.

However, from the inception of the doctoral program, these portfolios were assembled in large three-ring binders, duplicated for each dissertation committee member and then distributed among them. This method was not only cumbersome, it was inconsistent with the objectives of the assessment design, which is to situate students in the educational computing community of practice. Not only was the method low tech, it also precluded efficient communication and feedback between faculty advisors (masters within the community) and students (the participants). Thus, a critical element of its effectiveness as a situated cognitive approach was missing. Nor was this method conducive to communication among dissertation committee members concerning guidelines and expectations for the student. Ongoing interaction and guidance between student and faculty member needed to more seamlessly integrated into the process of creating the various artifacts for the portfolio.

These issues led to the design and development of an online, rubric-driven portfolio system that afforded users a technology-based means of distributing artifacts, communicating expectations, and obtaining feedback throughout the portfolio-building process. While interest in e-portfolios for meta-cognitive reflection and other instructional purposes abounds across educational levels (Barrett, 2007; Juniewicz, 2003; Pullman, 2002), the unique contribution of this electronic system 
is its basis on the theoretical foundation of situated and distributed cognition and its rubric-driven design.

\section{Rubric Development}

In keeping with the constructivist and situated approach that underlies the program, rubric development was delegated to doctoral students in the program. A small team of doctoral students met and examined program documents on portfolio guidelines, reviewed portfolios of doctoral program completers, collected example rubrics from other institutions or programs, and researched industry standards for practices exemplified by portfolio items.

This was not the first attempt to develop a rubric to standardize performance quality on the portfolio in this doctoral program. However, previous efforts had focused on creating individual rubrics for each artifact type: scholarly writing, professional presentations, and technology-based creative works. Design of a cohesive online system driven by the standards and expectations required a more comprehensive rubric design — one that could allow a degree of flexibility to promote the strengths of individual students yet maintain consistent quality performance standards among all students. The resulting rubric synthesizes the program guidelines concerning minimum artifacts of the various types, standards consistent with industry practice for assessing each artifact type, and a holistic, quantifiable scoring mechanism that assesses the entire body of work presented in the portfolio. Table 1 outlines the various artifacts required in a completed portfolio, as well as the required quantity of each artifact type and the standards used to assess each artifact.

Table 1: Summary of portfolio rubric requirements and standards

\begin{tabular}{|c|c|c|}
\hline Artifact & Portfolio Requirements & Assessment Standards \\
\hline $\begin{array}{l}\text { Curriculum } \\
\text { Vitae/Resume }\end{array}$ & $\begin{array}{l}\text { 1) Provide one example of either a } \\
\text { vitae or resume. } \\
\text { 2) Document should address but is not } \\
\text { limited to contact information, } \\
\text { education, professional experience, } \\
\text { research interests, honors and awards, } \\
\text { publications, and professional or civic } \\
\text { activities }\end{array}$ & $\begin{array}{l}\text { 1) Organized logically and is visually attractive } \\
\text { 2) Highlights or emphasizes key information } \\
\text { 3) Articulated concisely and accurately } \\
\text { 4) Includes accomplishments that are consistent with } \\
\text { student's goals } \\
\text { 5) Demonstrates student's participation in leadership } \\
\text { and service, as well as educational activities }\end{array}$ \\
\hline $\begin{array}{l}\text { Professional } \\
\text { Overview } \\
\text { (Reflective } \\
\text { Introduction) }\end{array}$ & $\begin{array}{l}\text { 1) Provide a 2-page professional } \\
\text { overview of and introduction to the } \\
\text { contents of the portfolio } \\
\text { 2) Include reflection on intellectual } \\
\text { growth, scholarly/research interests, } \\
\text { and professional goals. }\end{array}$ & $\begin{array}{l}\text { 1) Reflects on, describes, and documents student's } \\
\text { intellectual and professional growth } \\
\text { 2) Demonstrates the maturity and development it } \\
\text { intends to describe } \\
\text { 3) Outlines the student's research interests and } \\
\text { professional goals } \\
\text { 4) Relates portfolio contents to student's research } \\
\text { interests and goals } \\
\text { 5) Organized logically and developed fully } \\
\text { 6) Addresses an appropriate scholarly audience } \\
\text { 7) Adheres accurately to conventions of writing and } \\
\text { documentation }\end{array}$ \\
\hline
\end{tabular}




\begin{tabular}{|c|c|c|}
\hline Artifact & Portfolio Requirements & Assessment Standards \\
\hline $\begin{array}{l}\text { Scholarly } \\
\text { Writing }\end{array}$ & $\begin{array}{l}\text { 1) Include a minimum of } 6 \text { and a } \\
\text { maximum of } 10 \text { examples of scholarly } \\
\text { writing } \\
\text { 2) At least two examples must be } \\
\text { published or accepted for publication: } \\
\text { - One in a state or regional } \\
\text { peer-reviewed journal } \\
\text { - One in a national or } \\
\quad \text { international peer-reviewed } \\
\quad \text { journal } \\
\text { 3) All examples must be formatted } \\
\text { and documented according to } \\
\text { recognized guidelines }\end{array}$ & $\begin{array}{l}\text { 1) Fulfills its intended purpose (argue, compare, } \\
\text { review, analyze) } \\
\text { 2) Contributes to student's research agenda } \\
\text { 3) Reflects an understanding of foundations of the } \\
\text { discipline } \\
\text { 4) Based soundly on applicable theoretical } \\
\text { framework(s) } \\
\text { 5) Supported adequately with accurate and reliable } \\
\text { evidence } \\
\text { 6) Organized logically and developed fully } \\
\text { 7) Addresses an appropriate scholarly audience } \\
\text { 8) Adheres accurately to conventions of writing and } \\
\text { documentation }\end{array}$ \\
\hline $\begin{array}{l}\text { Professional } \\
\text { Presentations }\end{array}$ & $\begin{array}{l}\text { 1) Provide record of at least two, but } \\
\text { no more than five, presentations for } \\
\text { professional associations } \\
\text { 2) At least one must be from } \\
\text { presentation at a national or } \\
\text { international conference. } \\
\text { 3) Selection as a result of a } \\
\text { competitive process for all } \\
\text { presentations is recommended }\end{array}$ & $\begin{array}{l}\text { 1) Presented at a conference of appropriate caliber and } \\
\text { relevance } \\
\text { 2) Contributed as first, second, or third presenter } \\
\text { 3) Fulfills its intended purpose (argue, compare, } \\
\text { review, analyze) } \\
\text { 4) Contributes to student's research agenda } \\
\text { 5) Reflects an understanding of foundations of the } \\
\text { discipline } \\
\text { 6) Based soundly on applicable theoretical } \\
\text { framework(s) } \\
\text { 7) Supported adequately with accurate and reliable } \\
\text { evidence } \\
\text { 8) Organized logically and developed fully } \\
\text { 9) Addresses an appropriate scholarly audience }\end{array}$ \\
\hline $\begin{array}{l}\text { Technology- } \\
\text { based Creative } \\
\text { Works }\end{array}$ & $\begin{array}{l}\text { 1) Include at least two, but no more } \\
\text { than five, technology-based creative } \\
\text { projects } \\
\text { 2) Projects must demonstrate } \\
\text { commercial-quality creative effort } \\
\text { Example projects: computer based } \\
\text { training programs, research } \\
\text { simulations, Web sites, software } \\
\text { products }\end{array}$ & $\begin{array}{l}\text { 1) Contributed as first, second, or third developer } \\
\text { 2) Fulfills a unique purpose (instructional, } \\
\text { organizational, analytical/research) } \\
\text { 3) Addresses an established need (of a group, } \\
\text { organization, target audience) } \\
\text { 4) Contributes to student's research agenda } \\
\text { 5) Reflects an understanding of foundations of the } \\
\text { discipline } \\
\text { 6) Based soundly on applicable theoretical } \\
\text { framework(s) } \\
\text { 7) Demonstrates high quality in design and } \\
\text { implementation }\end{array}$ \\
\hline
\end{tabular}

\section{System Design}

The structure and goals of the rubric shaped the design of the online system. The student interface includes a "storage room" where students upload files to the system (See Figure 1) and then convert those files to portfolio artifacts (See Figure 2). From this point, files are then submitted to the online portfolio. 


\section{ARTIFACTS \& Files}

My Portfolio - My Files \& Artifacts - Log Out (imastudent)

\begin{tabular}{|c|c|c|}
\hline File Name & $\begin{array}{l}\text { Size } \\
\text { (kB) }\end{array}$ & Modified \\
\hline $\begin{array}{l}\text { Realism-Naturalness--Model for Physical and } \\
\text { Social Presence. doc }\end{array}$ & 103936 & $\begin{array}{l}\text { December } 27 \\
200615: 36: 10\end{array}$ \\
\hline $\begin{array}{l}\text { CCHA-Age of Empires for American } \\
\text { Identity.ppt }\end{array}$ & 70144 & $\begin{array}{l}\text { December } 27 \\
200615: 52: 57\end{array}$ \\
\hline Resume.doc & 65024 & $\begin{array}{l}\text { December } 27 \\
200615: 54: 11\end{array}$ \\
\hline SITE-MeasuringPresence.ttf & 82917 & $\begin{array}{l}\text { December } 27 \\
200615: 51: 33\end{array}$ \\
\hline
\end{tabular}

\section{Add File}

\begin{tabular}{lll} 
Send this file: & Browse... \\
\hline
\end{tabular}

Student Artifacts

Artifact Name Files

\section{Create Artifact}

Artifact Name

Figure 1: File upload and storage

\section{ARTIFACTS \& Files}

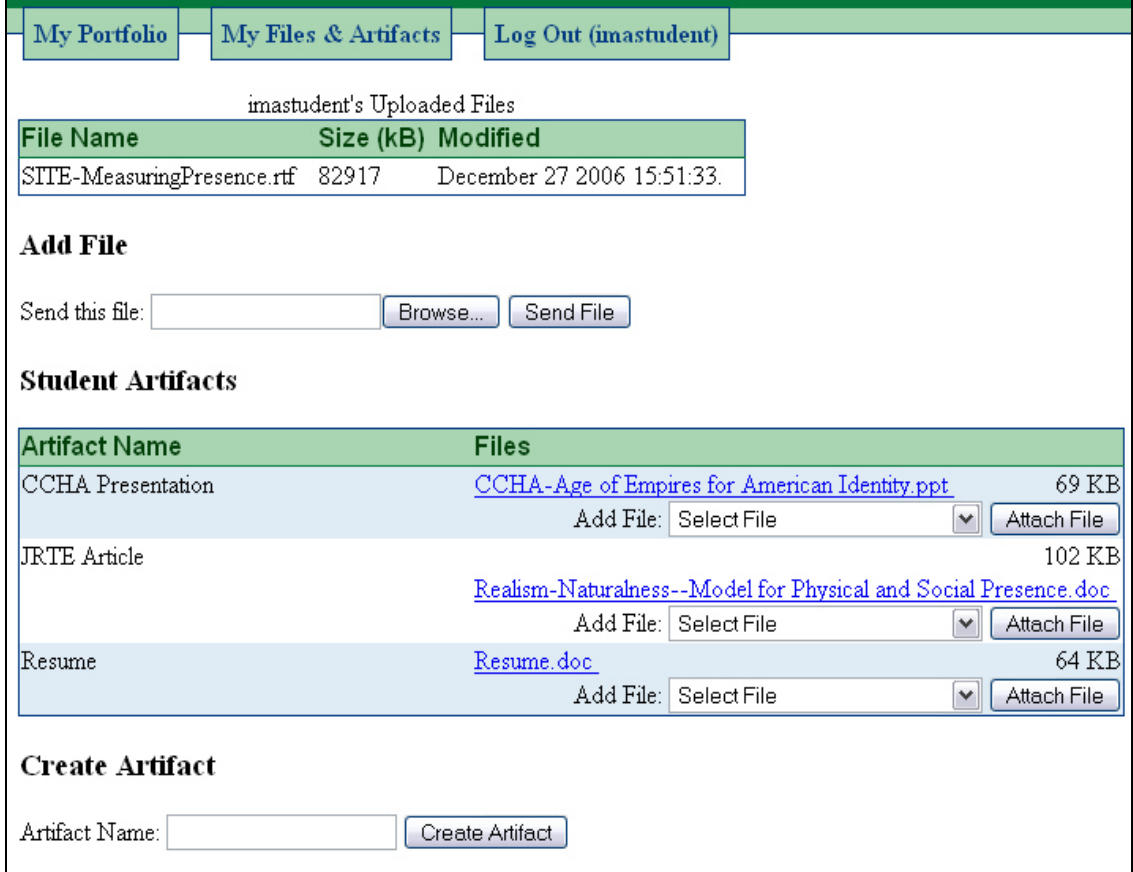

Figure 2: Artifact creation 
The online portfolio interface is organized by the rubric and subdivided into the sections by type of artifact, including a reflective introduction, curriculum vitae, scholarly writing, professional presentations, and technology-based creative works. Each section outlines the minimum and maximum number of artifacts that can be submitted to that section and details the performance standards or assessment criteria for that artifact type (See Figures 3 and 4). It also includes areas for comments on each artifact, so students can solicit and receive feedback from peers and committee members on each artifact as the portfolio is constructed throughout a student's coursework years. These comments and subsequent revisions are then documented within the system, preserving an archive of the ongoing dialogue between a student and his or her doctoral advisors throughout this phase of 'legitimate peripheral participation.'

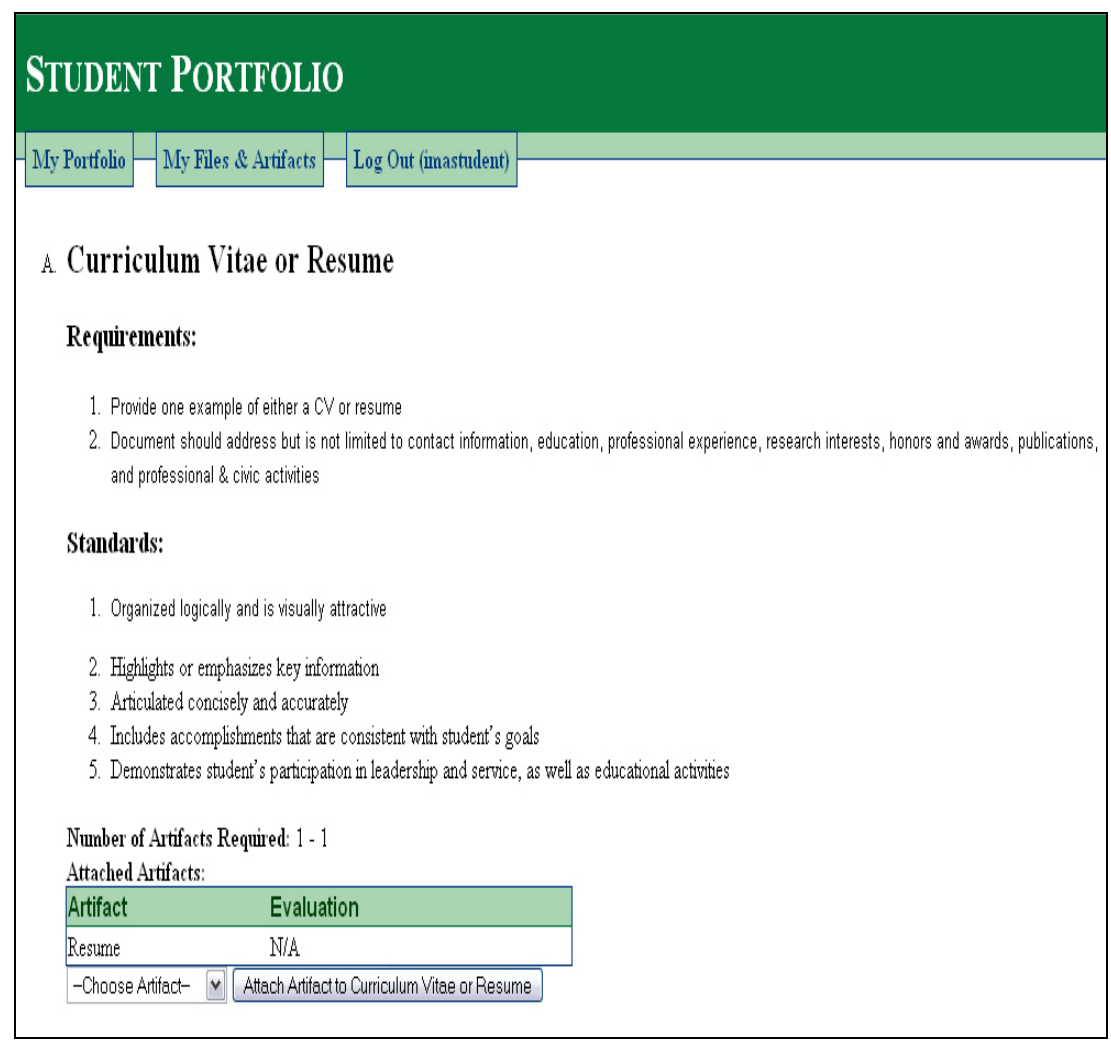

Figure 3: Portfolio interface - curriculum vitae 


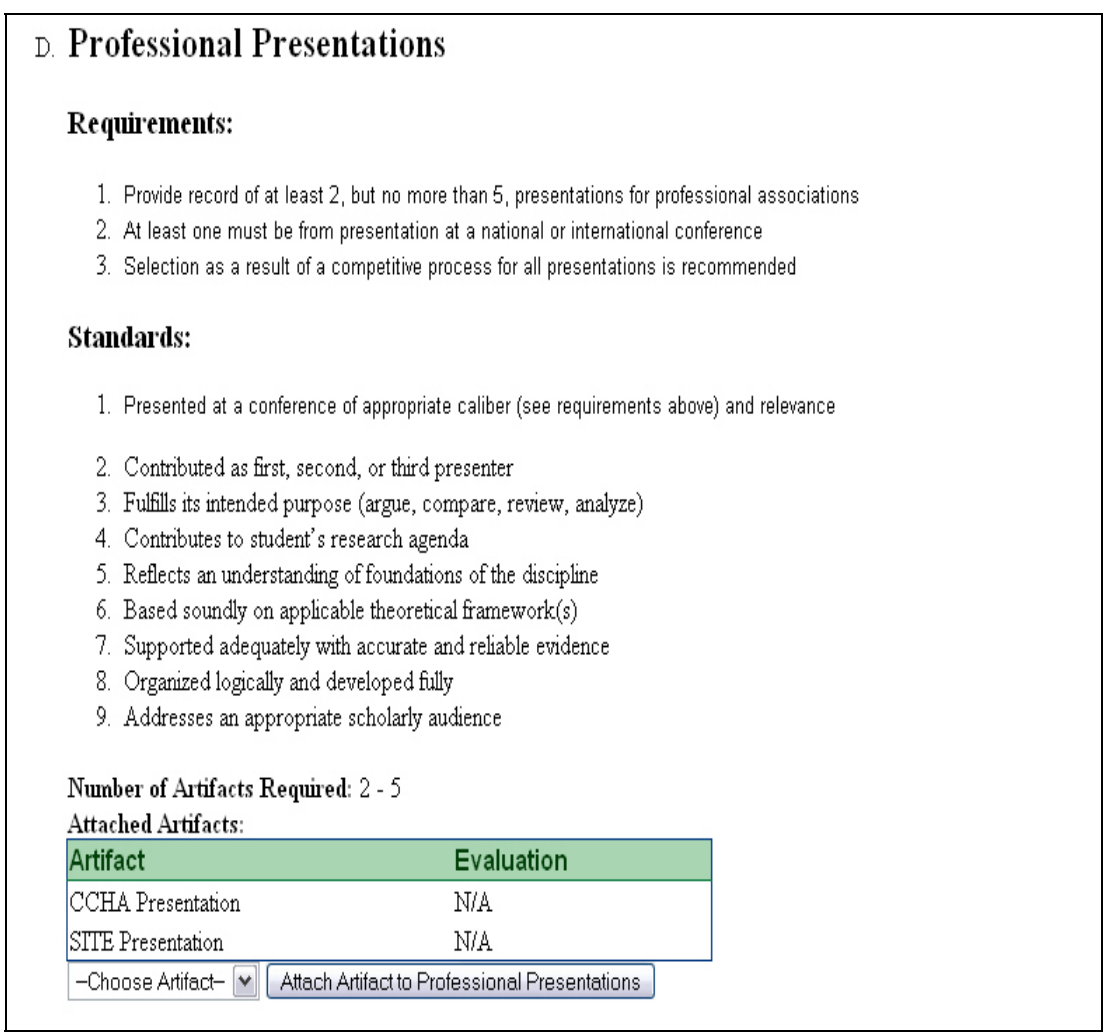

Figure 4: Portfolio interface - presentations

In the faculty members' interface, doctoral advisors "adopt" their student mentees (See Figure 5) and are able to construct a student's portfolio shell based on the rubric and tailor it to the student's strengths. 


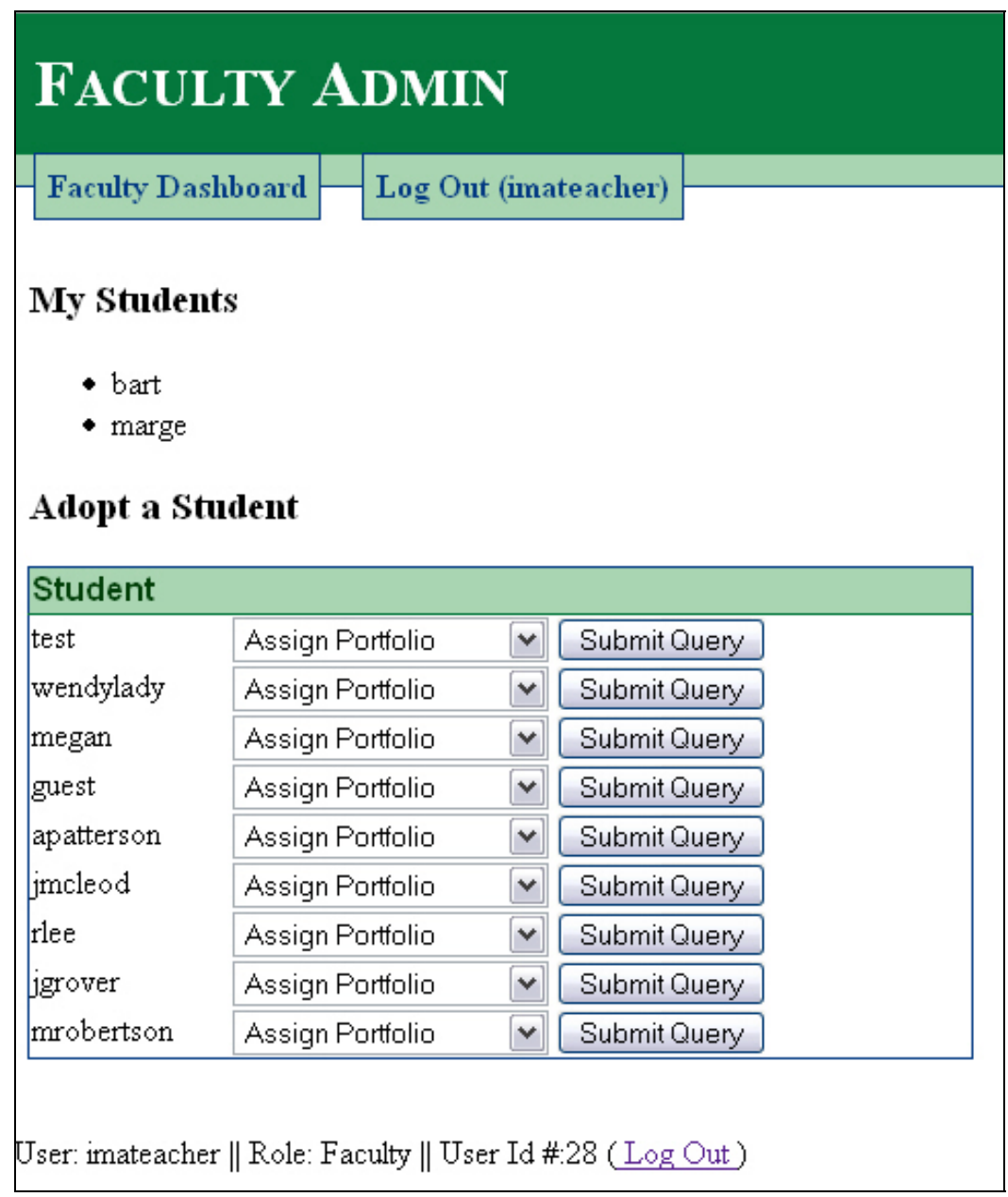

Figure 5: Faculty dashboard

For example, if a doctoral student is particularly talented in designing technology-based creative works, a faculty member might advise this student to focus his or her elective artifacts there by adjusting the artifact requirements in that area. Students still have to generate the minimum of each artifact type (as specified by program guidelines); however, the advising faculty member in this interface can set options for additional items beyond the minimums. Advisors can further clarify or add more specific performance standards to each section of the portfolio to further assist students in understanding and meeting those criteria. Faculty members also view student submissions and comment on those submissions. As discussed above, this commentary is archived in the system so that intended users have access to this vital dialogue.

\section{Benefits of the System}

The rubric-driven online portfolio system has several benefits over a paper-based system, beyond the advantages provided by digital distribution over bulky binders of collected works. The system also provides increased benefits to the doctoral students over the paper-based system. A technology-based system is more contextually authentic, situated as it is in a program in educational computing. Furthermore, according to Brown, Collins, and Duguid (1989), "Tools share several significant features with knowledge: They can only be fully understood through use, and using them entails both changing the user's view of the world and adopting the belief system of the cul- 
ture in which they are used" (p. 36). Students interact with the online system in assembling their portfolios and distribute assembled portfolios to their doctoral advisors digitally using computing tools that they will employ in their profession.

In addition to an authentic context, theories of situated cognition call for "assessments coupled with guidance based on expert modeling, situated mentoring, and legitimate peripheral participation" (Dede, Nelson, Ketelhut, Clarke, \& Bowman, 2004, p. 161). The rubric-driven, online portfolio system promotes engagement in the community of educational technology practice by providing a space for ongoing dialogue between masters and peripheral participants - the sociocultural interaction that proponents of situated cognition find so vital to knowledge construction (Duffy \& Cunningham, 1996; Lauzon, 1999; Lave \& Wenger, 1991; Vygotsky, 1978). Rather than distributing a completed portfolio to each advisor at the end of coursework, doctoral students can receive feedback on individual artifacts as they are loaded into the system and revise items prior to submission for publication or professional conferences. Students might also revise as needed to meet or exceed prescribed standards for the portfolio. The system allows faculty members to communicate the values and standards of this community of practice while providing the interaction critical to understanding and attaining them.

Finally, the assessment itself requires doctoral students to engage in the practices of an educational technologist. As Brown, Duguid, and Collins (1989) pointed out, "authentic activities, then, are most simply defined as the ordinary practices of the culture" (p. 38). They further argue that students learn best by "doing" (Brown et al., p. 32). Each artifact type within the Educational Computing Doctoral Portfolio represents an authentic activity relevant to the field: preparing a curriculum vitae, reflecting on goals and objectives, composing scholarly writing, presenting at conferences and workshops, and developing technology-based creative works. In the process of preparing portfolio artifacts, students both master their coursework and contribute to the construction of new knowledge for the educational technology field. Thus, they move from the role of legitimate peripheral participants to a more central role, gaining and constructing knowledge in the process (Duffy \& Cunningham, 1996; Lave \& Wenger, 1991).

\section{Conclusion}

Although the system is still in its early stages of development and testing, it shows tremendous promise for fulfilling its intended goals: providing a more consistent means of assessing performance (the rubric), offering a more contextually authentic means for distributing student-created educational computing artifacts, and promoting an ongoing dialogue between faculty members and doctoral students regarding the values and practices in the educational technology field. While further system testing, both technical and design-based, is yet to come, it is speculated that the system will have additional desirable outcomes. Such outcomes include increased student satisfaction with learning experiences during the coursework phase of the doctoral program, higher quality portfolio artifacts, enhanced student preparation for doctoral portfolio defense, and improved performance in educational research. Assessment of such outcomes, however, is an area for future research, pending full system release and participation from program faculty members and students. 


\section{References}

Barrett, H. C. (2007). Researching electronic portfolios and learner engagement: The REFLECT initiative. Journal of Adolescent \& Adult Literacy, 50(6), 436.

Bransford, J., Vye, N., Bateman, H., Brophy, S., \& Roselli, B. (2003). Vanderbilt's AMIGO Project: Knowledge of how people learn enters cyberspace. Retrieved 4/20/2004, 2004, from http://www.vanth.org/mmedia/vanth0103/vanth0103cd/papers/AmigoWFig.pdf

Brown, J. S., Collins, A., \& Duguid, P. (1989). Situated cognition and the culture of learning. Educational Researcher, 18(1), 32-42.

Cognition and Technology Group. (1990). Anchored instruction and its relationship to situated cognition. Educational Researcher, 19(8), 2-10.

Dale, E. (1946). Audiovisual methods in teaching (1st ed.). New York: Dryden Press.

Dede, C., Nelson, B., Ketelhut, D. J., Clarke, J., \& Bowman, C. (2004). Design-based research strategies for studying situated learning in a multi-user virtual environment. Proceedings of the 6th International Conference on Learning Sciences.

Dewey, J. (1925). Experience and nature. Chicago: Open Court Publishing.

Dewey, J. (1938). Experience and education. New York: Macmillan.

Duffy, T. M., \& Cunningham, D. J. (1996). Constructivism: Implications for the design and delivery of instruction. In D. H. Jonassen (Ed.), Handbook of research for educational communications and technology. New York: Macmillan.

Gibson, J. J. (1950). The perception of the visual world. Boston: Houghton Mifflin.

Gibson, J. J. (1979). The ecological approach to visual perception. Boston: Houghton Mifflin.

Harmon, S. W., \& Jones, M. G. (2001). An analysis of situated web-based instruction. Educational Media International, 38(4), 271-280.

Heidegger, M. (1996). Being and time: A translation of Sein und Zeit. Albany, NY: SUNY Press.

Juniewicz, K. (2003). Student portfolios with a purpose. Clearing House: A Journal of Educational Strategies, Issues and Ideas, 77(Nov-Dec), 73.

Lauzon, A. C. (1999). Situating cognition and crossing borders: Resisting the hegemony of mediated education. British Journal of Educational Technology, 30(3), 261.

Lave, J. (1988). Cognition in Practice: Mind, mathematics, and culture in everyday life. Cambridge, UK: Cambridge University Press.

Lave, J., \& Wenger, E. (1991). Situated learning: Legitimate peripheral participation. Cambridge, UK: Cambridge University Press.

Pullman, G. (2002). Electronic portfolios revisited: The efolios project. Computers and Composition, 19(2), 151.

Segers, M., Gijbels, D., \& Thurlings, M. (2008). The relationship between students' perceptions of portfolio assessment practice and their approaches to learning. Educational Studies, 34(1), 35.

Van Tartwijk, J., Driessen, E., Van Der Vleuten, C., \& Stokking, K. (2007). Factors influencing the successful introduction of portfolios. Quality in Higher Education, 13(1), 69.

Vygotsky, L. S. (1978). Mind in society. Cambridge, MA: Harvard University Press. 


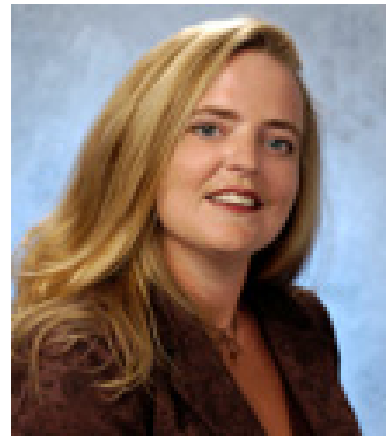

\section{Biographies}

Mary Jo Dondlinger is an instructional designer at Richland College of the Dallas County Community College District and a doctoral candidate at the University of North Texas, studying Learning Technologies and Community College Leadership. Her research and professional interests involve leveraging games, simulations, and Web 2.0 tools for learning, student engagement, and assessment of institutional effectiveness.

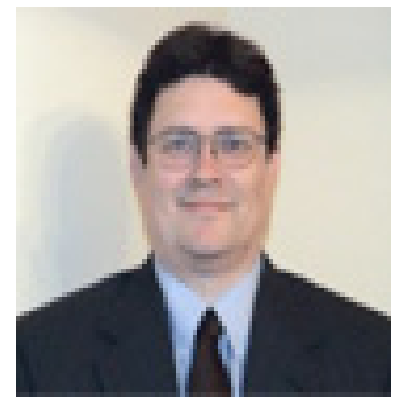

Greg Jones' interest is in expanding the way technology can be used to further the creation and distribution of knowledge and learning. His research focuses on the areas of emerging technologies for learning, which include visualization systems for education, virtual communities, telementoring, and 3D online learning environments (virtual environments). These technologies support learning by the distribution of interaction and feedback across both time and space via interactive forms of multimedia. http://courseweb.unt.edu/gjones 